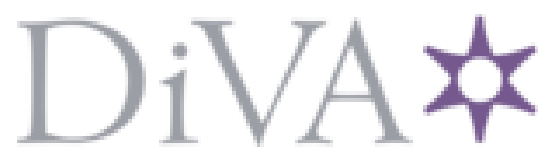

http://www.diva-portal.org

This is the published version of a paper published in .

Citation for the original published paper (version of record):

LI, X., Sosa, M., Olofsson, U. [Year unknown!]

A pin-on-discstudyofthetribologycharacteristicsofsinteredversusstandardsteelgearmaterials.

Access to the published version may require subscription.

N.B. When citing this work, cite the original published paper.

Permanent link to this version:

http://urn.kb.se/resolve?urn=urn:nbn:se:kth:diva-169932 


\title{
A pin-on-disc study of the tribology characteristics of sintered versus standard steel gear materials
}

\author{
Xinmin Li*, Mario Sosa, Ulf Olofsson \\ Department of Machine Design, Royal Institute of Technology (KTH), SE 10044 Stockholm, Sweden
}

\section{A R T I C L E I N F O}

\section{Article history:}

Received 21 July 2014

Received in revised form

11 December 2014

Accepted 20 January 2015

Keywords:

Gear material

Powder metallurgy

Wear

Friction

Damage mechanism

\begin{abstract}
A B S T R A C T
Though powder metallurgy (PM) allows manufacturing of complex components, including gears, we lack knowledge of the tribological performance of PM versus standard steel gear materials. Using a pin-ondisc machine, we simulate the sliding part of gear tooth contact in boundary and mixed lubricated regions, comparing the tribological characteristics of two sintered gear materials with those of a standard gear material. The comparison considered damage mechanisms, wear, and friction between these materials in different configurations (i.e., standard versus standard, sintered versus sintered, and sintered versus standard). The results indicate that, for pairings of the same gear materials, i.e., RS-RS (16MnCr5), AQ-AQ (Distaloy AQ+0.2\% C), and Mo-Mo (Astaloy $85 \mathrm{Mo}+0.2 \% \mathrm{C}$ ), RS has a lower friction coefficient. For PM and RS combinations, both PM pins have lower friction coefficients with RS disc material than do RS pins with PM disc materials. For the wear coefficient, at low and high speeds, RS pins always display better wear resistance than do AQ or Mo pins because of their high hardness and compacted microstructure. For RS-PM combinations, Mo pins display higher wear resistance than do AQ pins because their larger and more numerous pores enable good lubrication. Pins in the Mo-RS combination displayed the highest wear resistance, mainly because the pores in Mo discs hold lubricant, lubricating the contact surface and preventing adhesive wear. For the RS pin in the Mo-RS combination and the $\mathrm{AQ}$ pin in $\mathrm{RS}-\mathrm{AQ}$, the damage mechanism is slight adhesive wear and scuffing. For pins in the PM-PM, RS-PM, AQ-RS, and RS-RS combinations, the damage mechanism is a heavier scuffing-type adhesive wear.
\end{abstract}

(c) 2015 Elsevier B.V. All rights reserved.

\section{Introduction}

Powder metallurgy (PM) is usually used in manufacturing parts with complex geometries, such as gears and structural parts. The main attraction of PM is the high rate of material utilization, environmentally friendly production, economically especially for complex geometries and possibility of obtaining lighter components. PM steel gears do not behave like wrought steel gears in terms of fatigue and other mechanical properties, mainly reason lies in the pores remaining in the final product after PM gears are compacted, sintered, and heat treated. Porosity greatly influences the mechanical properties of sintered steels [1-3]. In addition, porosity at or near the surface influences the coefficients of friction and wear. Sonsino [4] found that the fatigue properties of PM components are inferior to those of wrought or cast parts. Cristofolin [5] focused on the effect of material variables (i.e., porosity and micro-hardness) and geometric parameters (i.e.,

\footnotetext{
* Corresponding author. Tel: + 46 701918177; fax: + 4687909137

E-mail address: xinmin@kth.se (X. Li).
}

contact length) on wear resistance in dry rolling-sliding contact. He built a knowledge base usable in the design step to take account of the effects of material variables (porosity and microhardness) and geometric parameters on wear resistance. Porosity influences PM materials by reducing the load-bearing surface and increasing the local plastic deformation, generating debris, and entrapping wear debris [6-11], all of which influence the wear behavior of PM materials. Govindarajan [12] investigated the lubricated rolling-sliding contact fatigue damage mechanisms of sintered steel material and found surface cracks opening up at higher rolling-sliding contact ratios. Straffelini [13], who claimed that the damage mechanisms of PM materials were controlled by large- and small-scale plastic deformations, also used a model to identify the damage mechanisms of PM materials under rollingsliding contact. Cristofolini [14] used dry rolling-sliding contact to analyze the wear mechanisms of PM materials, characterizing porosity under different manufacturing parameters to propose a design methodology for determining the mechanical properties of PM steel materials. Hoffman [15] found that changing from open to closed porosity in sintered steel significantly influences the 


\begin{tabular}{|c|c|c|c|}
\hline \multicolumn{2}{|c|}{ List of symbols } & $\rho, \rho_{o}$ & Density $\mathrm{kg} / \mathrm{m}^{3}$ \\
\hline PM & Powder metallurgy & $h_{0}$ & Minimum film thickness $\mathrm{m}$ \\
\hline RS & $16 \mathrm{MnCr} 5$ & $R^{\prime}$ & Reduced radius of curvature $\mathrm{m}$ \\
\hline$A Q$ & Distaloy $\mathrm{AQ}+0.2 \% \mathrm{C}$ & $E^{\prime}$ & Reduced Young's modulus Pa \\
\hline Mo & Astaloy $85 \mathrm{Mo}+0.2 \% \mathrm{C}$ & $N$ & Normal load $\mathrm{N}$ \\
\hline A-B & $\begin{array}{l}\text { The former is the disc material, the latter is the pin } \\
\text { material }\end{array}$ & $\begin{array}{l}v \\
\lambda\end{array}$ & $\begin{array}{l}\text { Sliding speed } \mathrm{m} / \mathrm{s} \\
\text { Film parameter }\end{array}$ \\
\hline$\mu$ & Friction coefficient & $R_{q B}, R_{q A}$ & RMS roughness $\mathrm{m}$ \\
\hline K & Wear coefficient $\mathrm{m}^{3} / \mathrm{N} \mathrm{m}$ & $V$ & Volume loss of the pin $\mathrm{m}^{3}$ \\
\hline$r$ & Radius of the pin tip mm & $h$ & Height of the worn part of the pin tip m \\
\hline$P_{\max }$ & Maximum contact pressure Gpa & $d$ & Diameter of the wear scar $\mathrm{m}$ \\
\hline$E_{1,2}$ & Young's modulus Pa & $S$ & Sliding distance $\mathrm{m}$ \\
\hline$\nu_{1,2}$ & Poisson's ratios & & \\
\hline
\end{tabular}

endurance limit, which affects the development of new, high-load structural parts such as planetary gears and camshaft lobes.

We lack knowledge of certain basic tribological characteristics of PM steel materials in gear applications, especially for standard gear steel in contact with PM gear steel. In this paper, we systematically compare tribological aspects (i.e., coefficient of friction, wear coefficient, and damage mechanisms) of both wrought and PM gear steels using pin-on-disc experiments.

\section{Experimental set-up}

\subsection{Pin-on-disc machine}

A pin-on-disc machine was used to simulate the sliding part of the gear contact. A schematic of the pin-on-disc machine is shown in Fig. 1. The pin-on-disc machine comprised a horizontal rotating disc and a calibrated dead-weight-loaded pin. In the present testing, the tip of the pin was in the form of a non-rotating half sphere.

The ambient environment was nearly the same for each test (see Table 1 for the test conditions). The friction force and vertical displacement of pin were automatically measured in the pin-on-disc machine using a load cell and a linear variable differential transformer (LVDT)

The experimental conditions are presented in Table 1. For all experiments, the normal load on the pin was the same and was set to $7 \mathrm{~N}$. Before the experiment, all specimens were cleaned in an ultrasonic bath, first rinsed in heptane, then rinsed in methanol, and finally dried in an oven. A syringe with a brush continuously applied the filtered ambient temperature lubricant with the aid of a pneumatic system.

\subsection{The test specimens}

The pin and disc specimens were manufactured from three gear materials: one standard gear steel and two PM materials. The chemical compositions of the materials are presented in Table 2. $\mathrm{RS}, \mathrm{AQ}$, and Mo will be used in the remainder of this paper to identify the three tested materials: $16 \mathrm{MnCr} 5$ (RS), Distaloy $\mathrm{AQ}+0.2 \% \mathrm{C}(\mathrm{AQ})$, and Astaloy $85 \mathrm{Mo}+0.2 \% \mathrm{C}$ (Mo). Both AQ and Mo specimens with density of $7200 \mathrm{~kg} / \mathrm{m}^{3}$ were sintered for $45 \mathrm{~min}$ at $1120{ }^{\circ} \mathrm{C}$ in $90 \%$ nitrogen and $10 \%$ hydrogen atmosphere. The mechanical parameters of the three materials are presented in Table 3. The standard gear steel, $16 \mathrm{MnCr} 5$, is a well-known wrought steel with easily identified elastic properties. For the sintered steels, the situation is more complicated. These materials are porous, and how they are manufactured determines their porosity and thereby their density and mechanical properties. According to Beiss [16], the elastic properties

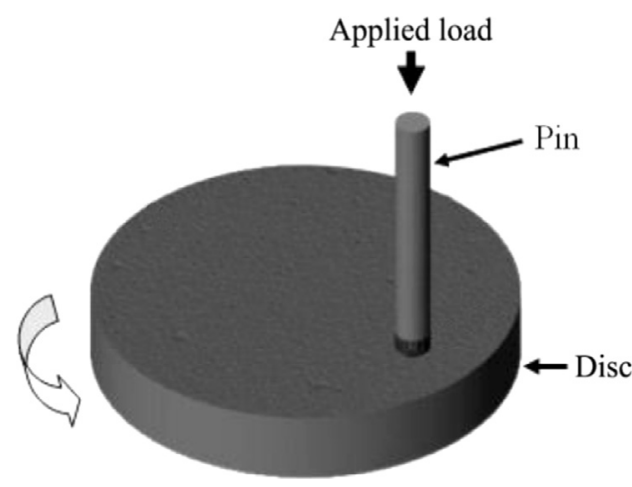

Fig. 1. Schematic of the pin-on-disc machine.

Table 1

Experimental conditions.

\begin{tabular}{lll}
\hline Temperature & $19 \pm 2$ & ${ }^{\circ} \mathrm{C}$ \\
\hline Relative humidity & $40 \pm 5$ & $\%$ \\
Normal load & 7 & $\mathrm{~N}$ \\
Radius of the pin tip $(r)$ & 5 & $\mathrm{~mm}$ \\
Disc diameter & 200 & $\mathrm{~mm}$ \\
\hline
\end{tabular}

Table 2

Chemical composition (mass \%) of RS, AQ and Mo gear materials.

\begin{tabular}{llllllllll}
\hline & Ni & Mn & Fe & C & S & P & Si & Cr & Mo \\
\hline RS & - & $1-1.3$ & $96.95-98.78$ & $0.14-0.19$ & $\leq 0.035$ & $\leq 0.025$ & 0.4 & 1.1 & - \\
AQ & 0.5 & 0.5 & 98.8 & 0.2 & - & - & - & - & - \\
Mo & - & - & 98.95 & 0.2 & - & - & - & - & 0.85 \\
\hline
\end{tabular}

Table 3

Characteristics of the specimens.

\begin{tabular}{llll}
\hline Specimen materials & RS & AQ & Mo \\
\hline Young's modulus (GPa) & 210 & 154 & 154 \\
Poisson's ratio & 0.3 & 0.28 & 0.28 \\
Surface hardness (pin) (HV) & 945 & 782 & 804 \\
RMS surface roughness (disc) $(\mu \mathrm{m})$ & 0.0598 & 0.0606 & 0.0685 \\
RMS surface roughness $($ pin) $(\mu \mathrm{m})$ & 0.097 & 0.0897 & 0.0923 \\
\hline
\end{tabular}

of PM steel materials can be calculated using the following formulas:

$E=E_{o}\left(\rho / \rho_{o}\right)^{3.4}$

$\nu=\left(\rho / \rho_{o}\right)^{1.6}\left(1-\nu_{o}\right)-1$ 
where $\rho_{0}, E_{0}$, and $v_{o}$ are the density, Young's modulus, and Poisson's ratio, respectively, of solid steel. Fig. 2 presents a photograph of the disc and pin samples used in the present experiments. All the specimens were case hardened.

The lubricant used was BP Castrol Syntrans 75W-80. Table 4 presents detailed specifications of the lubricant. To simulate the sliding part of the contact correctly, the surface roughness of the disc and pin was close to that prescribed for gears in DIN quality level 5 [17].

\subsection{Contact conditions and test procedure}

The tests aimed to simulate the sliding tooth contact conditions of an FZG gear test. In this case, the normal load ( $7 \mathrm{~N}$ ) was set to produce a moderate load that created maximum contact pressures of $900 \mathrm{MPa}, 800 \mathrm{MPa}$, and $720 \mathrm{MPa}$ for the RS-RS, RS-PM/PM-RS, and PM-PM material combinations, respectively. The maximum contact pressure can be calculated according to Stachowiak [18]:

$P_{\max }=\frac{3 N}{2 \pi a^{2}}$

where $a$ is radius of the contact area:

$a=\left(\frac{3 N R^{\prime}}{E^{\prime}}\right)^{\frac{1}{3}}$

where $R^{\prime}$ and $E^{\prime}$ are the reduced radius of curvature and the reduced Young's modulus, respectively. $R^{\prime}$ and $E^{\prime}$ are defined as:

$\frac{1}{R^{\prime}}=\frac{1}{R_{X}}+\frac{1}{R_{Y}}$

$\frac{1}{E^{\prime}}=\frac{1}{2}\left[\frac{1-v_{1}^{2}}{E_{1}}+\frac{1-v_{2}^{2}}{E_{2}}\right]$

where $E_{1,2}$ is the Young's modulus and $v_{1,2}$ is Poisson's ratio for the pin and disc, respectively. $R_{X}$ and $R_{Y}$ are the radii of curvature in $X$ and $Y$ direction, as for this pin on disc experiment $R_{1 X}=R_{1 Y}=$ $5 \times 10^{-3} \mathrm{~m} ; R_{2 X}=R_{2 Y}=\infty \mathrm{m}$.

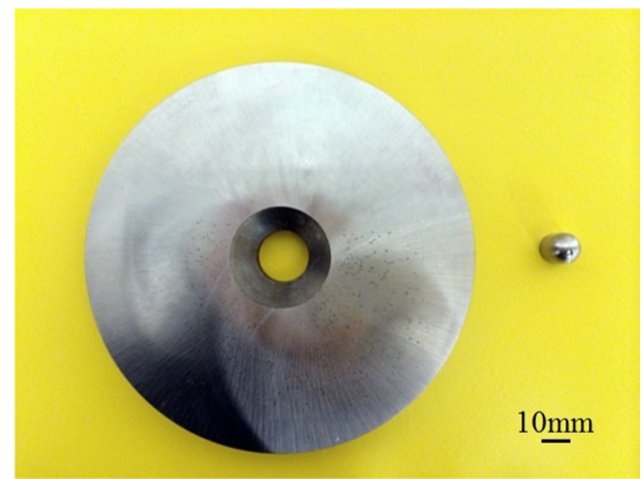

Fig. 2. Pin and disc specimens.

Table 4

Test lubricant

\begin{tabular}{ll}
\hline Lubricant name & BP Castrol Syntrans 75W-80 \\
\hline SAE viscosity grade & 64 \\
Kinematic viscosity at $40^{\circ} \mathrm{C}\left(\mathrm{mm}^{2} / \mathrm{s}\right)$ & 52.3 \\
Kinematic viscosity at $100^{\circ} \mathrm{C}\left(\mathrm{mm}^{2} / \mathrm{s}\right)$ & 9.2 \\
Density at $15^{\circ} \mathrm{C}\left(\mathrm{kg} / \mathrm{m}^{3}\right)$ & 837 \\
Pressure-viscosity coefficient, $\alpha\left(\mathrm{mm}^{2} / \mathrm{N}\right)$ & $1.79 \times 10^{-8}$ \\
Dynamic viscosity, $\eta(\mathrm{Pa})$ & $42.7 \times 10^{-3}$ \\
\hline
\end{tabular}

$\frac{1}{R_{X}}=\frac{1}{R_{1 X}}+\frac{1}{R_{2 X}}$

$\frac{1}{R_{Y}}=\frac{1}{R_{1 Y}}+\frac{1}{R_{2 Y}}$

The material characteristics of the specimens are shown in Table 3.

Using the formula for calculating the minimum film thickness in elastohydrodynamic contacts derived by Hamrock and Dowson [19], the minimum film thickness $\left(h_{0}\right)$ for a circular contact can be calculated:

$\frac{h_{0}}{R^{\prime}}=3.63\left(\frac{v \eta}{E^{\prime} R^{\prime}}\right)^{0.68}\left(\alpha E^{\prime}\right)^{0.49}\left(\frac{N}{E^{\prime} R^{\prime 2}}\right)^{-0.073}\left(1-e^{-0.68 k}\right)$

where $v$ is the sliding speed and $\eta$ is the dynamic viscosity of the lubricant at $40{ }^{\circ} \mathrm{C}$. $k$ is the elliptical parameter and in circular contact it is 1 . The detailed characteristics of the test lubricant are presented in Table 4. By varying the sliding velocity, we can obtain different minimum film thicknesses. The general relationship between the friction coefficient and the film parameter $(\lambda$, i.e., the ratio of the film thickness and the RMS value of the roughness amplitude) is represented by the Stribeck curve (Fig. 3). The film parameter is calculated as:

$\lambda=\frac{h_{0}}{\sqrt{R_{q A^{2}}+R_{q B}^{2}}}$

where $h_{o}$ is the lubricant film thickness and $R_{q B}$ and $R_{q A}$ are the RMS roughness of the two surfaces in contact, respectively.

The $A-B$ formulation will be used in the remainder of this paper to identify the materials of disc and pin, the former letter identifying the disc material and the latter the pin material. The test conditions are shown in Table 5.

The various test conditions are also indicated in Fig. 3.

\subsection{Test procedure}

A total of 6 discs and 36 pins, as shown in Fig. 2, were used for the experiments in the test matrix presented in Table 6.

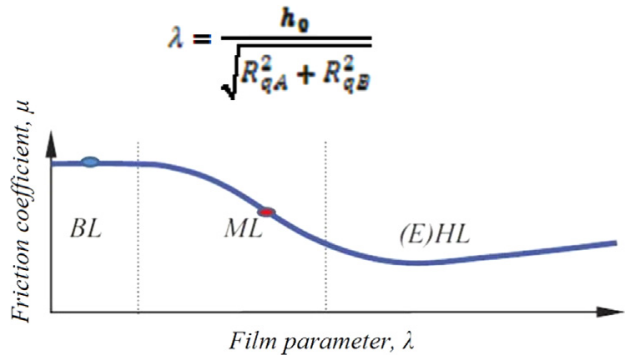

Fig. 3. Coefficient of friction, $\mu$, versus film parameter, $\lambda$, in the lubricated sliding of metals. $B L=$ boundary lubrication, $M L=$ mixed lubrication, $(E) H L=$ elastohydrodynamic lubrication. Blue and red dots indicate test conditions. (For interpretation of the references to color in this figure legend, the reader is referred to the web version of this article.)

Table 5

The test conditions

\begin{tabular}{llll}
\hline $\begin{array}{l}\text { Test } \\
\text { conditions }\end{array}$ & $\begin{array}{l}\text { Maximum contact pressure } \\
P_{\max }(\mathrm{MPa})\end{array}$ & $\begin{array}{l}\text { Film } \\
\text { parameter } \lambda\end{array}$ & $\begin{array}{l}\text { Sliding velocity } \\
(\mathrm{m} / \mathrm{s})\end{array}$ \\
\hline 1 (RS-RS) & 900 & 0.5242 & 0.5 \\
$2(\mathrm{RS}-\mathrm{RS})$ & 900 & 2.1558 & 4 \\
$3(\mathrm{RS}-\mathrm{PM})$ & 800 & 0.5331 & 0.5 \\
$4(\mathrm{RS}-\mathrm{PM})$ & 800 & 2.1922 & 4 \\
$5(\mathrm{PM}-\mathrm{PM})$ & 720 & 0.5436 & 0.5 \\
$6(\mathrm{PM}-\mathrm{PM})$ & 720 & 2.2354 & 4 \\
\hline
\end{tabular}


Table 6

Pin-on-disc test matrix.

\begin{tabular}{|c|c|c|c|c|}
\hline Test no. & Disc material & Pin material & Sliding speed (m/s) & $\begin{array}{l}\text { Maximum contact } \\
\text { pressure (MPa) }\end{array}$ \\
\hline $1-2$ & RS & RS & 0.5 & 900 \\
\hline $3-4$ & RS & RS & 4 & 900 \\
\hline $5-6$ & RS & $\mathrm{AQ}$ & 0.5 & 800 \\
\hline $7-8$ & RS & $\mathrm{AQ}$ & 4 & 800 \\
\hline $9-10$ & RS & Mo & 0.5 & 800 \\
\hline $11-12$ & RS & Mo & 4 & 800 \\
\hline $13-14$ & AQ & RS & 0.5 & 800 \\
\hline $15-16$ & $\mathrm{AQ}$ & RS & 4 & 720 \\
\hline $17-18$ & AQ & AQ & 0.5 & 720 \\
\hline 19-20 & $\mathrm{AQ}$ & $\mathrm{AQ}$ & 4 & 720 \\
\hline $21-22$ & $A Q$ & Mo & 0.5 & 720 \\
\hline $23-24$ & $\mathrm{AQ}$ & Mo & 4 & 720 \\
\hline $25-26$ & Mo & RS & 0.5 & 800 \\
\hline $27-28$ & Mo & RS & 4 & 800 \\
\hline $29-30$ & Mo & $\mathrm{AQ}$ & 0.5 & 720 \\
\hline $31-32$ & Mo & $A Q$ & 4 & 720 \\
\hline $33-34$ & Mo & Mo & 0.5 & 720 \\
\hline $35-36$ & Mo & Mo & 4 & 720 \\
\hline
\end{tabular}

Each test was performed twice to ensure repeatability. Each test comprises three steps: the sliding distance was $600 \mathrm{~m}$ in the first step, $1800 \mathrm{~m}$ in the second, and $3600 \mathrm{~m}$ in the third. The surface topography of the test disc was measured between each step using a stylus instrument. The stylus measurement results will be used in a separate running-in study and will not be further discussed here.

\subsection{Calculation of friction and wear coefficients}

The friction coefficient was calculated from the measured friction force divided by the normal load exerted on the pin by the testing machine's dead weight.

The wear scar diameter was measured using optical microscopy in the ordinate and abscissa directions at the end of each test. The volume removed from the pin surface can then be calculated using the following method. The main parameters used in calculating the volume loss are shown in Fig. 4.

The volume loss, $V$, of the pin, which is half-spherical in shape, is calculated by:

$V=\pi h^{2}\left(r-\frac{h}{3}\right)$

where $d$ is the diameter of the wear scar, $r$ is the radius of the halfsphere, and $h$ is the height of the wear volume, which can be calculated as:

$h=r-\left(r^{2}-\left(\frac{d}{2}\right)^{2}\right)^{\frac{1}{2}}$

Archard's wear model is used here:

$\frac{V}{S}=K N$

where $V$ is the volume loss in $\mathrm{m}^{3}$ on the contact surface, $S$ is the sliding distance in $\mathrm{m}, K$ is the specific wear coefficient $\left(\mathrm{m}^{2} / \mathrm{N}\right)$, and $N$ is the normal load in $\mathrm{N}$. Reformulating this gives:

$K=\frac{V}{N S}$

Note that the wear coefficient used in this study is the mean of that determined in each of three steps of the test procedure.

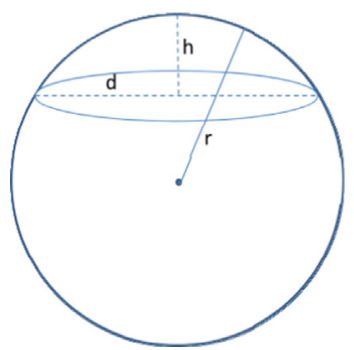

Fig. 4. The wear scar.

\subsection{Surface measurement and material studies}

After the test, the tested specimens were measured using a Taylor Hobson Form Talysurf to determine the surface roughness of the contacting part of the pin specimen. The specimens were also examined using SEM to obtain micrographs for studies of the damage mechanisms. An optical measuring microscope (Nikon model MM-60/L3) was used to acquire optical micrographs. An optical microscope was also used to measure the diameter of the worn surfaces of the pins and for porosity studies of the PM materials. A micro-hardness tester (Matsuzawa MMT-7) was used to determine hardness profiles of the pin specimens.

\section{Results}

\subsection{Friction coefficient results}

To obtain an overview of the test results, we first present the mean values of all the tests and the deviation will be shown in Section 4. Mean values of two repeats were calculated at each step of the test procedure, that is, for the first $600 \mathrm{~m}$, then $1800 \mathrm{~m}$, and finally $3600 \mathrm{~m}$ of sliding. The friction coefficient results of tests $1-$ 13, 13-24, and 25-36 are shown in Fig. 5. The disc material is regular steel (RS), the PM gear steel referred to as AQ and the PM gear steel referred to as Mo. The test material combinations and speeds are presented in Table 6. From Fig. 5 it is obvious that the friction coefficients during the high-speed (i.e., $4 \mathrm{~m} / \mathrm{s}$ ) tests were consistently lower than those during the low-speed tests (i.e., $0.5 \mathrm{~m} / \mathrm{s}$ ) regardless of the material combination. Note the very low friction coefficient for the AQ pin in contact with the RS or Mo disc.

\subsection{Wear coefficient results}

The wear coefficient results are presented in Fig. 6, which shows the mean value and standard deviation for each test condition. Most of the low-sliding-speed tests indicate a higher wear coefficient than do the tests conducted at the higher sliding speed. Obviously, regardless of the disc material, the RS material always has the lowest wear coefficient at both sliding speeds. Fig. 8 (right) shows that the Mo-RS combination has the lowest wear coefficient at both sliding speeds.

\subsection{Surface analysis}

Figs. 7-9 present 3D surface roughness results for the contacting part of all pin specimens after testing; the area of the image is $0.1 \times 0.1 \mathrm{~mm}^{2}$. We can identify several phenomena here, such as pores in the PM pin shown in Fig. 7b, c, and f and in Fig. 8b and c. In addition, parallel traces found in most images in Figs. 7-9 indicate an adhesive wear mechanism such as scuffing.

Fig. 10 shows SEM micrographs of RS pins. Note that it is problematic to analyze PM pins in an SEM because the lubricant residue in the pin pores can contaminate and destroy the equipment; 

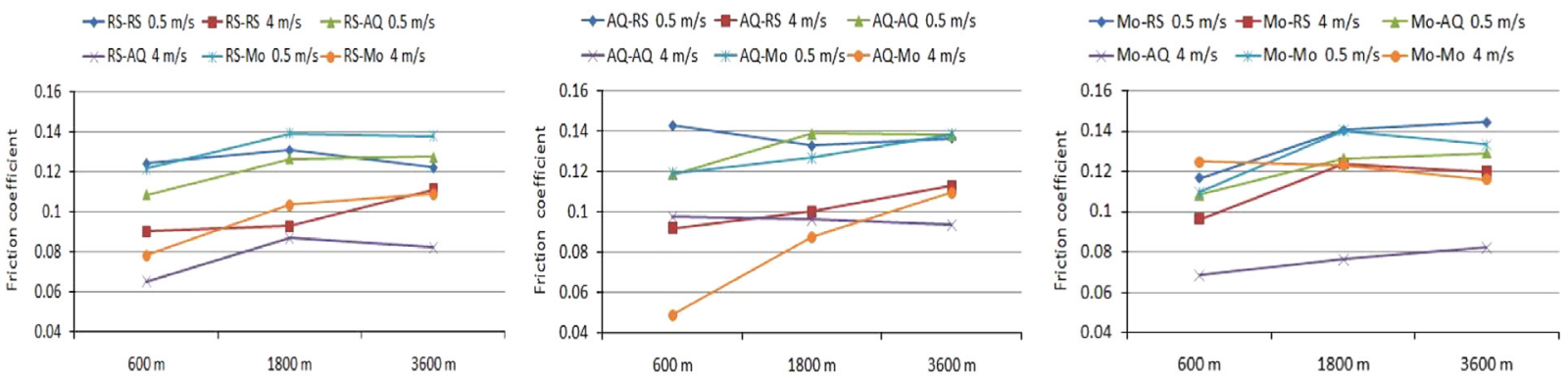

Fig. 5. Friction coefficient results (mean value) of tests 1-36.
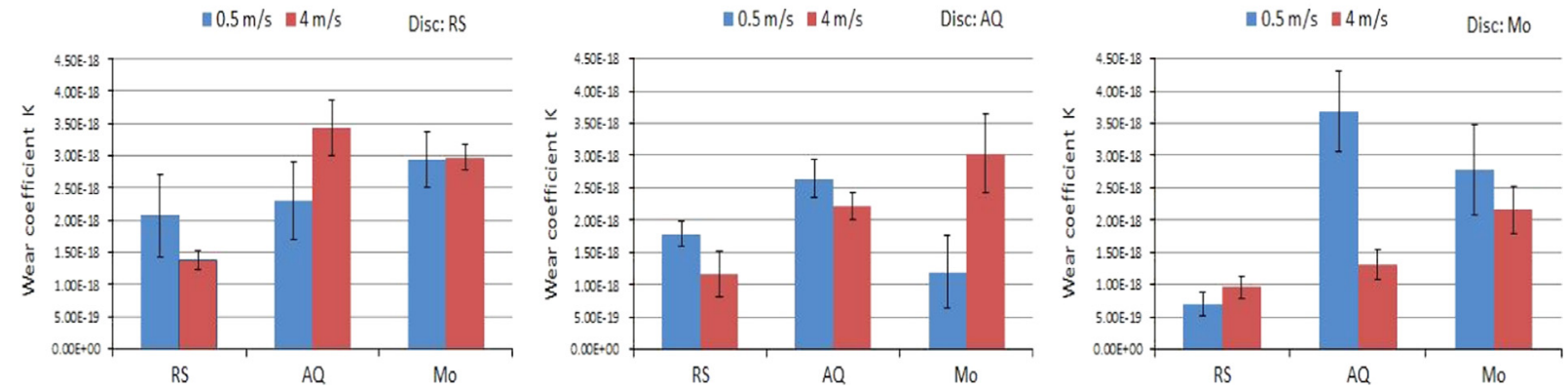

Fig. 6. Wear coefficient (mean value and standard deviation) results for different material combinations.
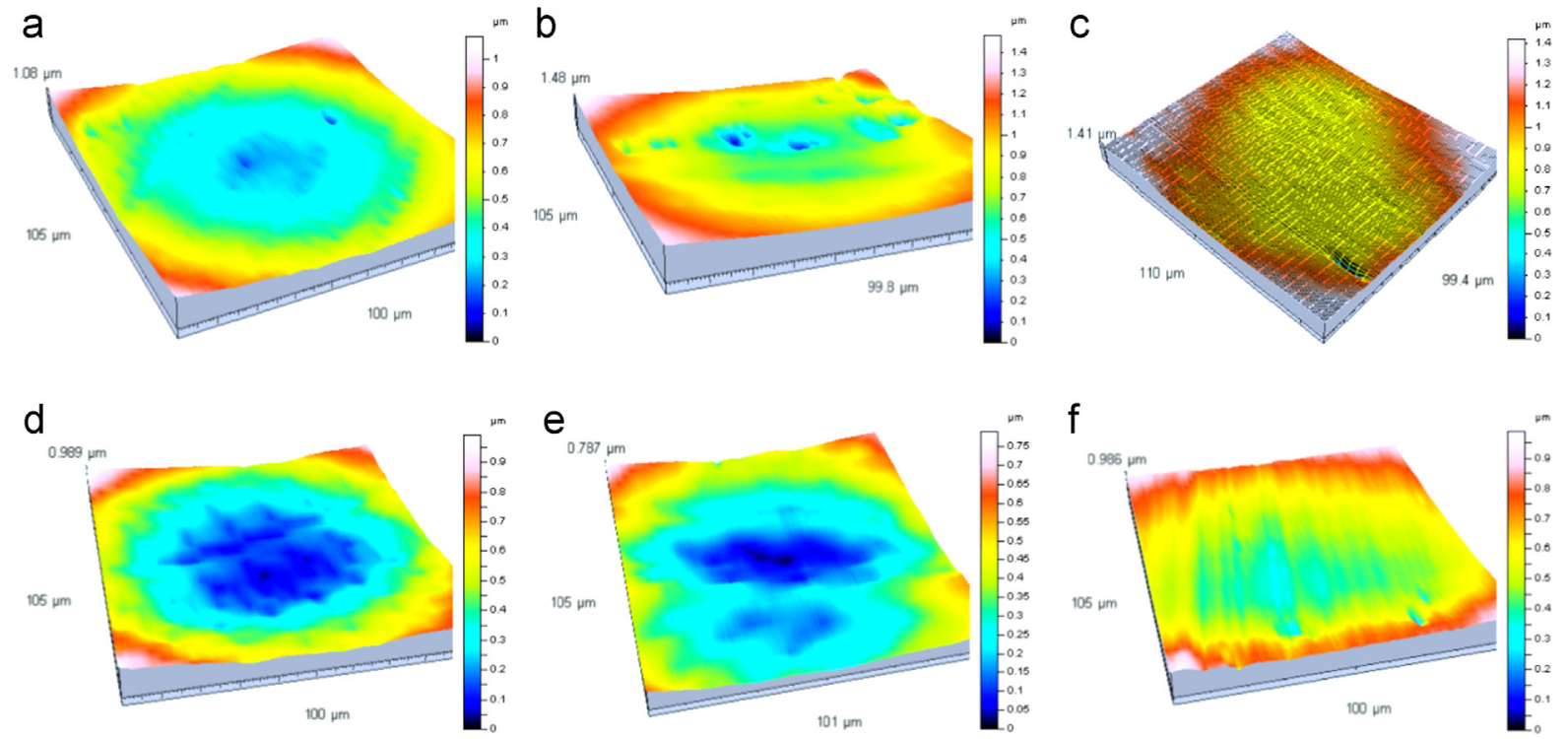

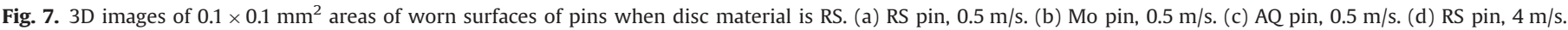
(e) Mo pin, $4 \mathrm{~m} / \mathrm{s}$. (f) AQ pin, $4 \mathrm{~m} / \mathrm{s}$.

nevertheless, one PM pin of AQ material was analyzed in an SEM as shown in Fig. 11. The parallel traces visible in the SEM micrographs indicate the same damage mechanism, i.e., scuffing, as shown by the 3D surface topography measurements. Also visible in the SEM pictures are pieces of material transferred to the surface, indicating adhesive wear, as shown in Figs. 10c and 11.

The hardness measurements were made near the tip of the new pin specimens (HV 0.1). The hardness-depth curve shown in Fig. 12 indicates that the RS material is harder than either the AQ or Mo material. In addition, the Mo material is nearly as hard as is the AQ material above a depth of $0.5 \mathrm{~mm}$

Fig. 13 shows the porosity structure of $A Q$ and Mo pins. Note that the Mo material has larger and more numerous pores both on the surface and in the bulk material. Differences in porosity on or near the surface may influence the friction and wear coefficients.

\section{Discussion}

\subsection{Friction results and mechanisms}

The lambda value $(\lambda)$ shown in Fig. 3 measures the severity of the asperity contact during lubricated sliding. Between these regimes, when $1<\lambda<3$, is a mixed lubrication regime under which the load is carried partly by the asperities and partly by the lubricating oil. In the test run at the high sliding speed of $4 \mathrm{~m} / \mathrm{s}$, the $\lambda$ value was approximately 2.2 , indicating a mixed lubrication regime. At a low speed of $0.5 \mathrm{~m} / \mathrm{s}$, a boundary lubrication regime dominated at $\lambda=0.5$. This difference in lubrication regime explains the results presented in Fig. 5, where the friction coefficient was always lower in the highspeed tests conducted in the mixed lubrication regime than in the low-speed tests conducted in a boundary lubrication regime. 
a

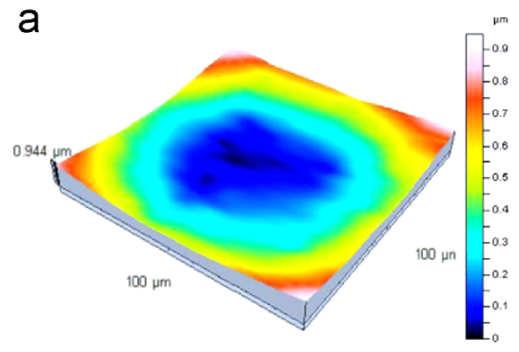

b

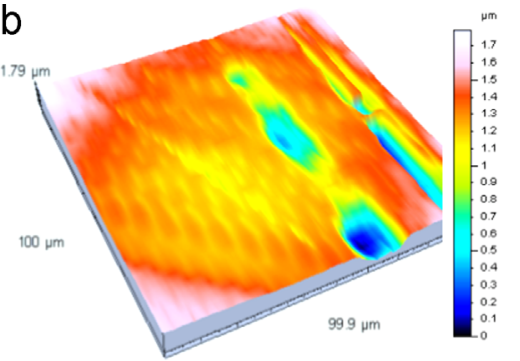

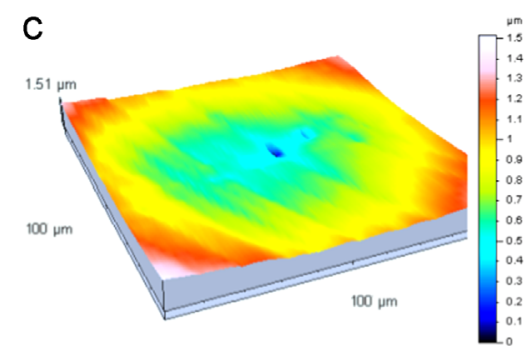
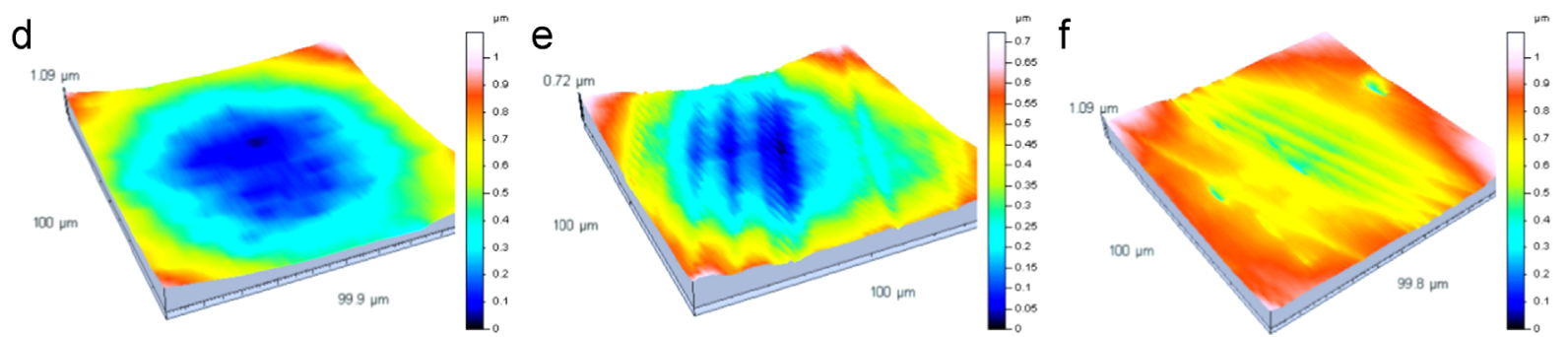

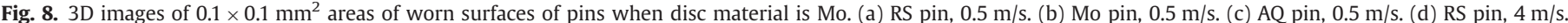
(e) Mo pin, $4 \mathrm{~m} / \mathrm{s}$. (f) AQ pin, $4 \mathrm{~m} / \mathrm{s}$.
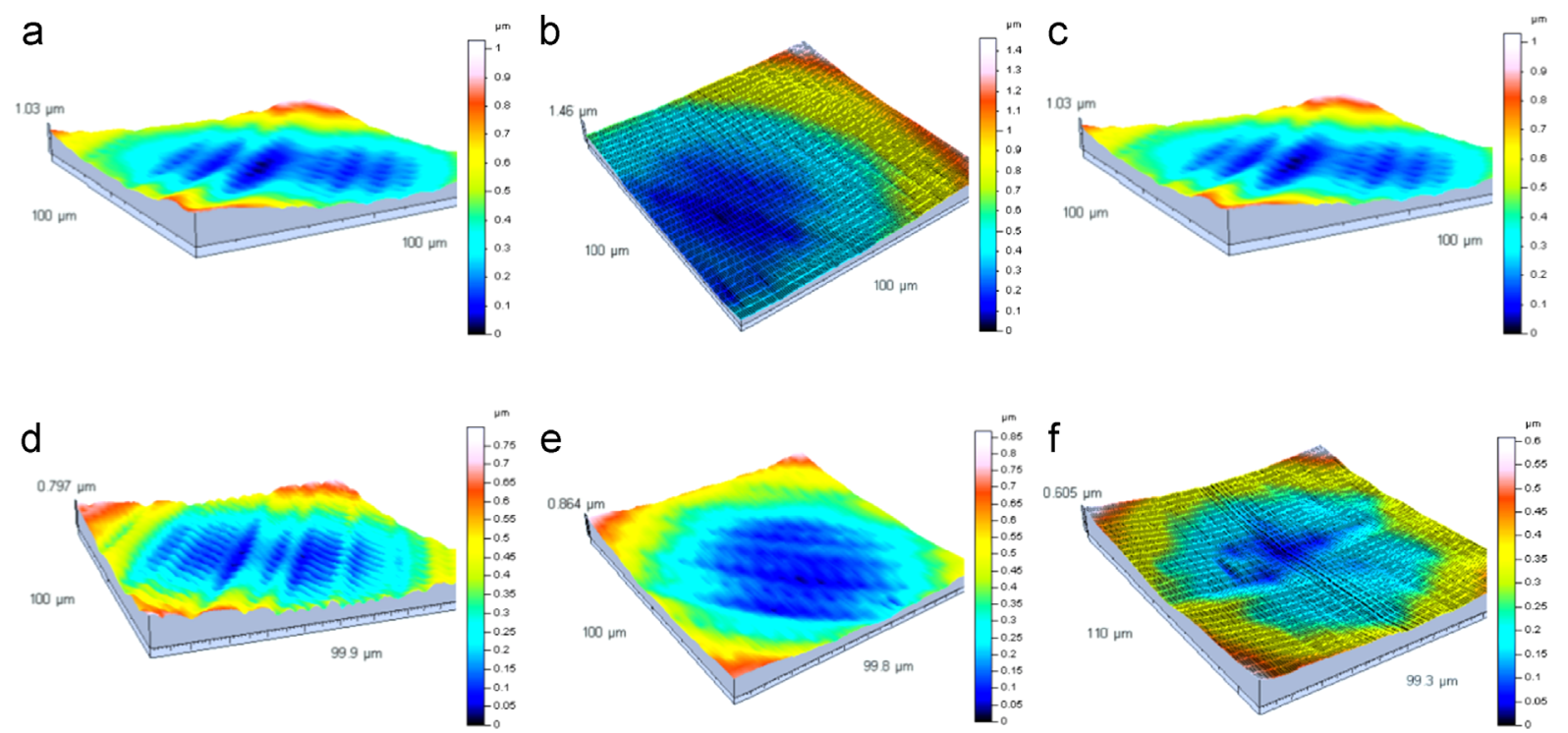

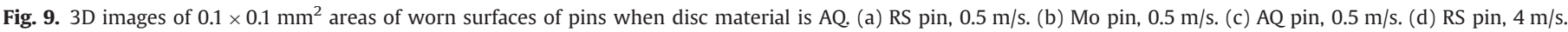
(e) Mo pin, $4 \mathrm{~m} / \mathrm{s}$. (f) AQ pin, $4 \mathrm{~m} / \mathrm{s}$.

Fig. 5 show that the friction coefficient tended to increase in most of the tests. In boundary lubrication, all the loads are carried by asperity contact. At first, an oxide layer exists, so the friction coefficient is somewhat lower; this oxide layer eventually wears away, leading to more metal-to-metal contact and a more adhesive friction mechanism, possibly resulting in a higher friction coefficient. In the meantime, as wear is developing, considerable debris [6-11] may enter into the pin-disc contact. The presence of debris between the contact surfaces somewhat enhances the surface roughness in an indirect way, giving a transiently lower value of $\lambda$.

Fig. 14 shows the friction coefficient results for RS-RS, AQ-AQ and Mo-Mo material combinations. Under boundary lubrication conditions, the PM material obviously has a higher friction coefficient. This is because the rougher surfaces of the PM-PM combination and debris of PM pins can also increase the friction coefficient. As shown in Fig. 8b, the Mo-Mo combination results in a rougher surface than does the RS-RS material combination (Fig. 7a). Fig. 9c shows 3D images of the AQ-AQ combination. The pins in the RS-RS and $\mathrm{AQ}-\mathrm{AQ}$ combinations have nearly the same surface roughness; however, the AQ pin wears more and this may lead to more debris, contributing to a higher friction coefficient than that of the RS-RS combination. Asperity contact carries most of the load in boundary lubrication, so the surfaces of pins of all materials are easily worn in this regime. In addition, the RS material is harder than the PM material, and higher hardness means higher wear resistance. The PM pins are easily worn and may produce more wear particles. Further research is necessary to quantify the differences in wear debris between PM and RS material and their influence on the friction coefficient.

In mixed lubrication, the trend of the friction coefficient is not so obvious. Both PM and RS pins have nearly the same degree of surface smoothness.

Fig. 15 shows the friction coefficient results of testing combinations of RS and PM gear materials. Note that both combinations are 

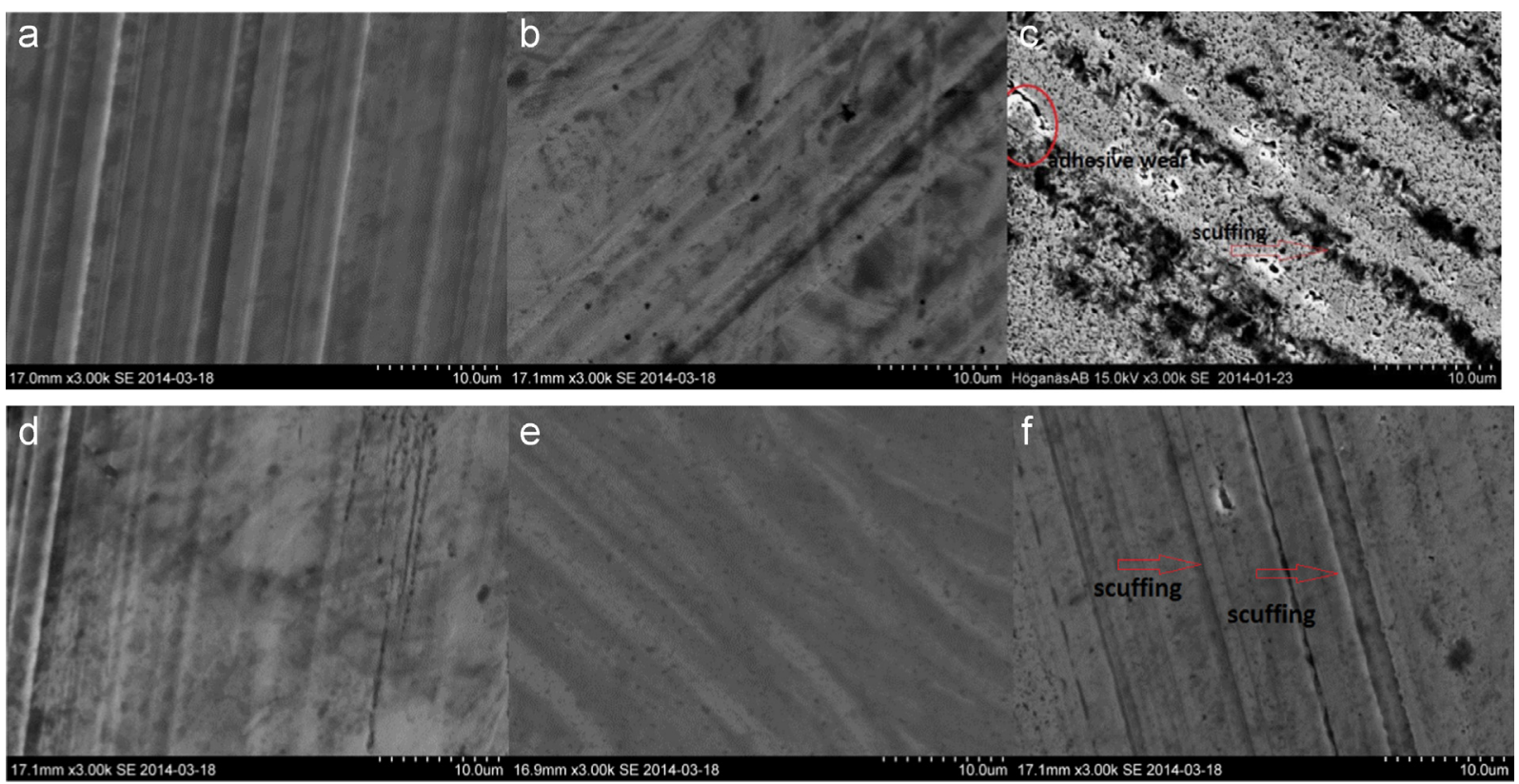

Fig. 10. SEM micrographs of RS pins: (a) RS-RS $0.5 \mathrm{~m} / \mathrm{s}$, (b) AQ-RS $0.5 \mathrm{~m} / \mathrm{s}$, (c) Mo-RS $0.5 \mathrm{~m} / \mathrm{s}$, (d) RS-RS $4 \mathrm{~m} / \mathrm{s}$, (e) AQ-RS $4 \mathrm{~m} / \mathrm{s}$, and (f) Mo-RS $4 \mathrm{~m} / \mathrm{s}$.

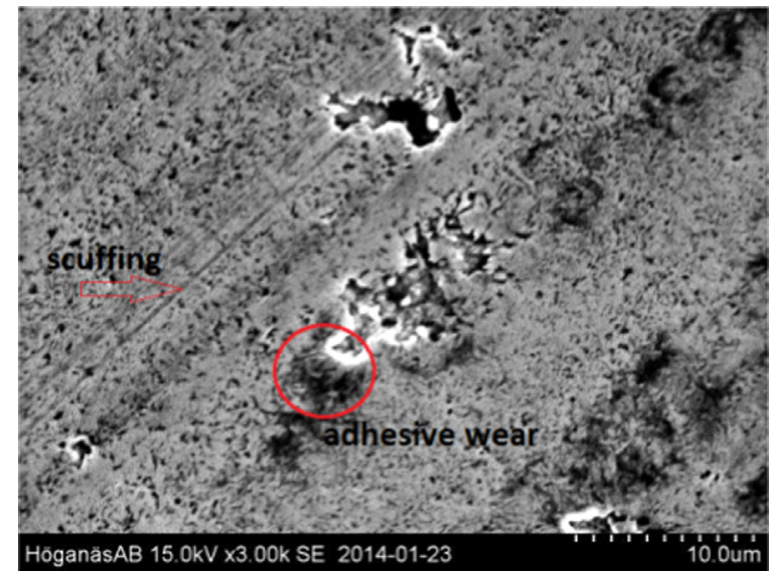

Fig. 11. SEM micrograph of the AQ pin in the RS-AQ combination at $4 \mathrm{~m} / \mathrm{s}$.

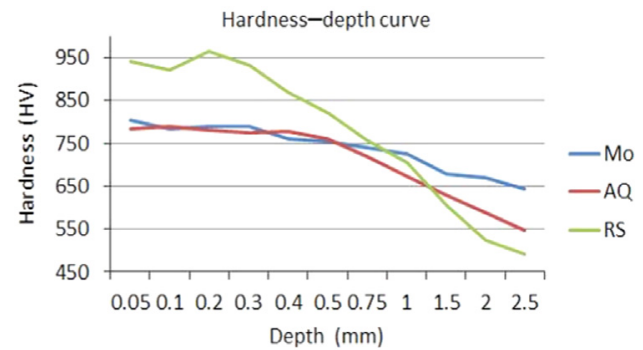

Fig. 12. Hardness-depth curves for new pin specimens (HV 0.1) of the three materials.

shown in each diagram, that is results for PM materials as pin and regular steel materials RS as disc and the opposite RS as pin and PM gear materials as disc is compared in each diagram. Each diagram presents the mean and standard deviation of the friction coefficient for each step. The results indicate that the AQ-RS and Mo-RS material combinations always have higher friction coefficients than do the RS-AQ and RS-Mo combinations, respectively, mainly because of the unique microstructure of PM materials. As the sliding continues, the increased pin temperature may have several effects, i.e., the pin's mechanical properties will change, its rate of oxidation will increase, and phase transformation may occur, all of which will influence the friction behavior. As shown in Fig. 13, PM specimens contain many pores and have a specific porosity structure. When the disc is rotating, lubricant constantly enters and exits the pores on the contact surface of PM pins, improving the heat dissipation and preventing the mechanical properties of PM specimens from changing. Furthermore, the lubricant contained in the pores of PM pins can provide good lubrication conditions. RS specimens, however, do not dissipate heat as well as PM specimens do, and the higher temperature somewhat worsens the friction properties of RS pins. PM pins therefore always have lower friction coefficients than do RS pins. Here further research is necessary to generalize these results to studies on gear test samples for gear efficiency studies.

Fig. 16 compares the friction coefficient results of AQ and Mo pins, the disc materials being RS and Mo. With RS and Mo discs (see Fig. 16), AQ pins always have lower friction coefficients than do Mo material pins at both high and low speeds. Given the porosity structure shown in Fig. 13, it is obvious that Mo pins have more and larger pores in the bulk material than do the AQ pins. In that case, Mo pins can easily have rougher surfaces after running for some time, leading to a higher coefficient of friction. With the AQ disc (see Fig. 5 c) there is no obvious trend, AQ and Mo pins give nearly the same friction results.

As shown in Fig. 5, regardless of the disc material, the AQ pin specimens have the lowest friction coefficients in most material combinations in both boundary and mixed lubrication regimes. This may be because of its porosity structure, which may promote heat dissipation and good lubrication. This is a meaningful finding for gear transmission efficiency.

\subsection{Wear results and damage mechanism}

\subsubsection{Wear results}

Fig. 17 shows the wear coefficient results for all material combinations. Among pairings of the same materials at both low and high speeds (see Fig. 17a), pins in the RS-RS combination always display 

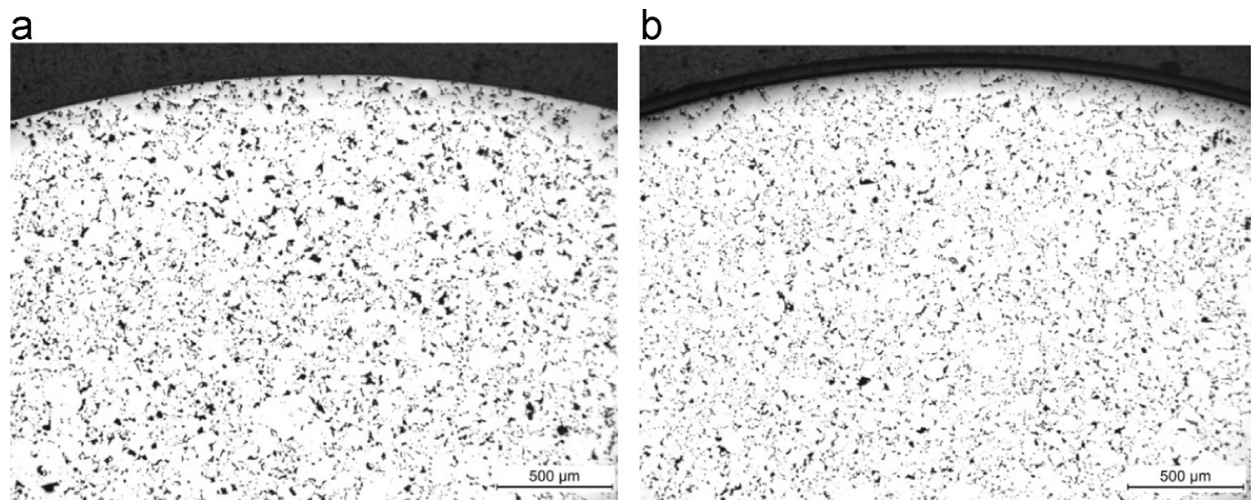

Fig. 13. Porosity structure of PM pins: (a) Mo and (b) AQ.
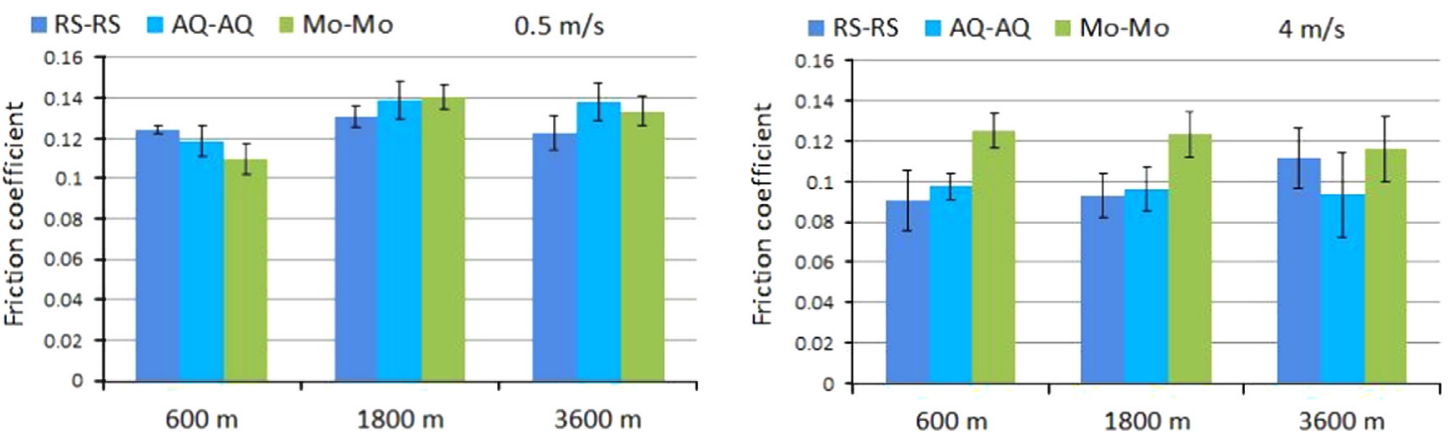

Fig. 14. Friction coefficient results (mean value and standard deviation) for same material combinations at different speeds.
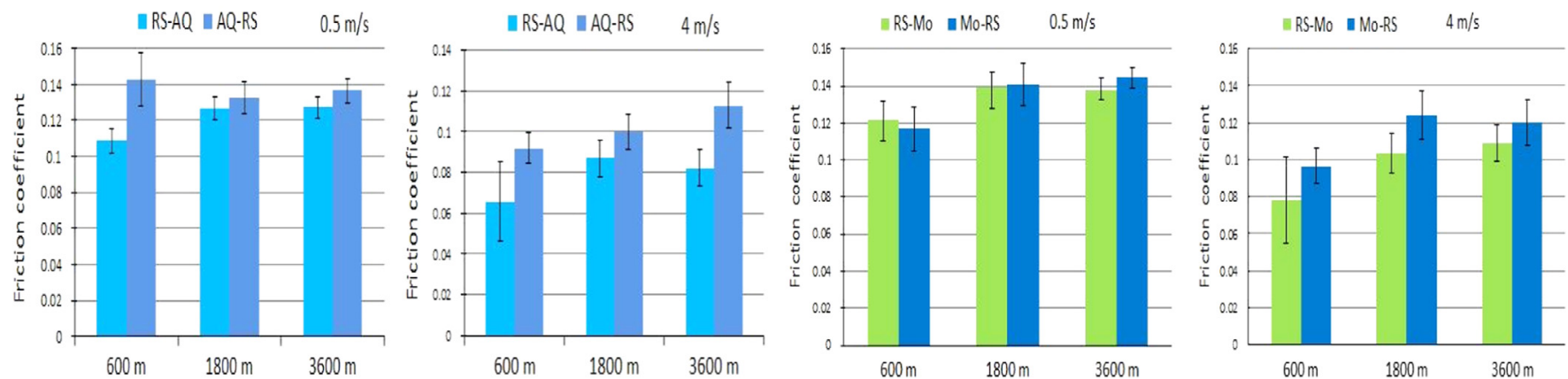

Fig. 15. Friction coefficient (mean value and standard deviation) results for RS and PM material combinations.
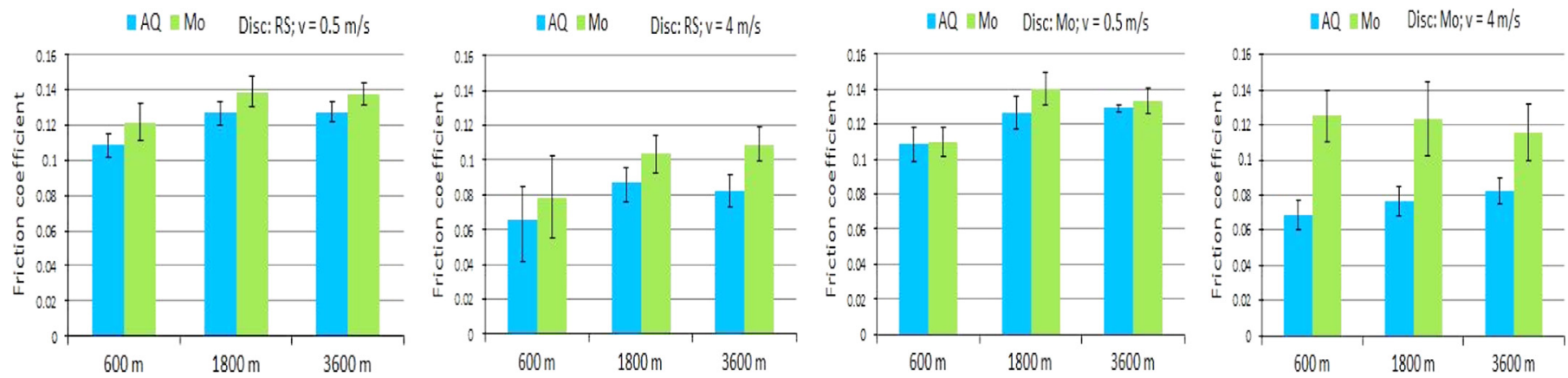

Fig. 16. Friction coefficient results (mean value and standard deviation) of AQ and Mo pins.

better wear resistance than do pins in the AQ-AQ and Mo-Mo combinations. Bergseth et al. [20] studied wear in a pin-on-disc machine, obtaining wear coefficients of the same orders as those presented here.

Given the hardness-depth curve shown in Fig. 12, we see that the RS material is harder than both AQ and Mo materials, which have similar near-surface hardness profiles. Higher hardness is beneficial for wear resistance. The compacted microstructure also contributes to the lower wear coefficient of the RS-RS material combination. Given the porosity structure shown in Fig. 13, the AQ and Mo materials clearly contain many pores. The resulting somewhat more open microstructure of the AQ and Mo materials make them more easily worn than the RS material. In addition, the pores in the AQ and Mo materials influence the roughness of the 
a

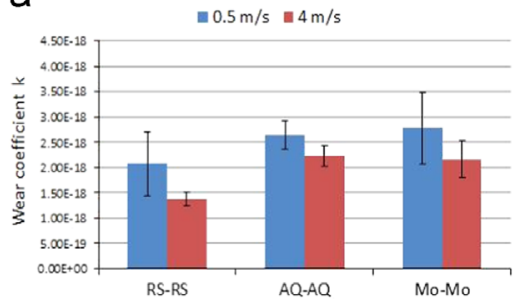

b

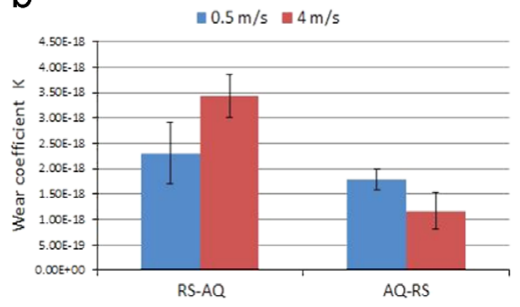

C

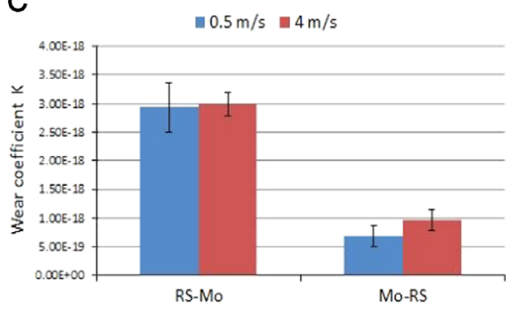

Fig. 17. Wear coefficient results: (a) same materials in pins and discs, (b) RS-AQ and (c) RS-Mo.

contact surfaces, which are case hardened and ground in all specimens. After reasonable sliding distances, the originally ground and somewhat smooth surfaces become worn. The pores make the surface rougher (Figs. 7a and 8b show that the Mo pin has a rougher surface than does the RS pin), providing more opportunities for asperity contact. Direct asperity contact can enhance the wear coefficient. AQ-AQ and Mo-Mo material combinations have nearly the same wear coefficient. The higher wear resistance of RS material comes from its higher hardness and compacted microstructure. The higher wear coefficient of PM materials results from their more open microstructure, lower hardness, and rougher contact surfaces due to the presence of pores. In AQ-AQ and Mo-Mo combinations, pins of $A Q$ and Mo have nearly the same wear coefficient.

From Fig. 17 we can compare the wear coefficients of RS pins when the disc materials are RS, AQ, and Mo. The pins in the AQ-RS and Mo-RS combinations have successively lower wear coefficients than that of the RS-RS combination. The main reason for this is that the pores in AQ and Mo discs contain lubricant that can lubricate the contact surface well, preventing adhesive wear. Different material contact can prevent adhesive wear. Mo disc produced the lowest wear coefficient in an RS pin, largely because the larger and more numerous pores in the Mo disc held more lubricant, better lubricating the contact surfaces. PM-RS combinations therefore merit examination in future gear research; in particular, the Mo-RS combination displays good potential.

Fig. 17 shows that most mixed lubrication conditions result in higher wear resistance than do boundary lubrication conditions. As shown in Table 5 , low-sliding-speed experiments have a $\lambda$ value of approximately 0.51 (in the boundary lubrication region) while high-sliding-speed experiments have a $\lambda$ value of approximately 2.2 (in the mixed lubrication region). All loads are carried by asperity contact in boundary lubrication, but in the mixed lubrication region, parts of the load are carried by the lubricant film. Here, the low sliding speed leads to a boundary lubrication regime that causes more severe wear.

\subsubsection{Damage mechanism}

Wear refers to the loss of material from a contact surface. Depending on the specific wear mechanism, wear is of four types: abrasive wear, adhesive wear, surface fatigue, and corrosion wear. Abrasive wear refers to the damage to contact surfaces caused by hard particles between the contact surfaces. These hard particles may come from the contact components or the outside environment. The degree of abrasive wear increases with increasing relative speed, load, and the hardness of the hard particles. Adhesive wear is material transfer caused by partial melt of the contact surface at high temperatures. Fatigue wear refers to micro-cracks caused by contact stress concentration and plastic deformation due to the long-term effects of cyclic loads. As these micro-cracks expand and intersect, peeling happens. Corrosion wear refers to the loss of surface material due to chemical or electrochemical reactions between the contacting surface material and the surrounding medium.
From the wear results shown in Fig. 17, it is clear that the MoRS material combination has the highest wear resistance. Fig. 8a and d show no obvious grooves on the pins' surfaces, so no heavy scuffing occurred due to adhesive wear. However, 3D images of other material combinations, for example, Fig. 7d and f and Fig. 8c, show deep parallel grooves that provide evidence of heavy adhesive wear, such as scuffing. Carefully examining Fig. 10c and f reveals adhesive wear occurring under boundary lubrication conditions. The shallow grooves shown in Fig. 10c indicate slight scuffing-type adhesive wear under boundary lubrication conditions: under these conditions, the load is completely carried by asperity contact, which provides great opportunities for scuffing. In mixed lubrication, as shown in Fig. 10f, only slight scuffing occurs. Fig. 17 shows that pins in the AQ-RS combination have somewhat higher wear resistance than do pins in the RS-RS combination. As for the damage mechanism, the deep grooves shown in Fig. 9a and d (also Fig. 10b and e) indicate that scuffing has occurred. There are several possible explanations why, when the disc and pin materials are PM and RS, respectively, the RS pins always display higher wear resistance. First, the RS material is harder than the PM materials, as shown in Fig. 12. Second, different material combinations can effectively prevent the occurrence of adhesive wear. Finally, the microstructure of PM materials includes pores full of lubricant between pin and disc contact surfaces; lubricant from these pores can lubricate the contact surfaces, helping prevent adhesive wear.

As for the mechanism of damage to the AQ pin in the RS-AQ combination, the SEM micrograph of the AQ pin in Fig. 11 shows signs of slight scuffing-type adhesive wear.

When it comes to the PM-PM, RS-PM, AQ-RS, and RS-RS material combinations, the damage mechanism differs completely from that in the Mo-RS combinations. Figs. 7-9 clearly show heavy scuffing on the surfaces of the pins in the PM-PM, RS-PM, AQ-RS, and RS-RS combinations. Fig. 10 shows SEM micrographs of RS pins, in which it is clear that there are scuffing-type adhesive wear and material transfer.

\section{Conclusion}

The sliding part of gear tooth contact was simulated in pin-ondisc experiments. The friction properties, wear resistance, and damage mechanisms of two PM steel gear materials and a regular steel gear material were investigated and compared. The following conclusions could be drawn from the study:

- The friction and wear coefficients in the high-speed $(4 \mathrm{~m} / \mathrm{s})$ tests are consistently lower than in the low-speed tests $(0.5 \mathrm{~m} /$ s) regardless of the material combination. This is probably due to a mixed lubrication regime in the high-speed tests and a boundary lubrication regime in the low-speed tests.

- The AQ-RS (AQ disc and RS pin) and Mo-RS (Mo disc and RS pin) combinations always have higher friction coefficients than do the RS-AQ (RS disc and AQ pin) and RS-Mo (RS disc and Mo 
pin) combinations. The main reason for this is the more open microstructure of the PM materials, whose pores can contain lubricant that improves lubrication and heat dissipation.

- When the disc material is RS or Mo, AQ pins always have lower friction coefficients than do Mo pins at both high and low speeds. The RS-AQ combination is a potential candidate for improving the gear transmission efficiency.

- At both high and low speeds, RS pins always display better wear resistance than do AQ and Mo pins because of both their high hardness and compacted microstructure.

- In RS-PM combinations, Mo pins display higher wear resistance than do AQ pins because the microstructure of Mo can provide more lubricant, enabling better lubrication and heat dissipation than in AQ pins.

- Pins in the Mo-RS combination displayed the highest wear resistance of any pins in all gear material combinations. This was mainly because the pores in Mo discs contain lubricant that can lubricate the contact surfaces and prevent adhesive wear. The Mo-RS combination could usefully be applied in gear transmissions.

- The surfaces of RS pins in the Mo-RS combination and of AQ pins in the RS-AQ combination show some indications of adhesive wear. For the pins in the PM-PM, RS-PM, AQ-RS, and RS-RS combinations, the damage mechanism is more severe adhesive wear, such as scuffing.

\section{Acknowledgments}

Thanks are expressed to Dr. Michael Andersson from Höganäs $A B$ for his guidance and technological support. This project was financially supported by Höganäs AB.

\section{References}

[1] G. Hoffmann, C.M. Sonsino, K. Michaelis, Rolling Contact Fatigue - Component Design and Testing for P/M Applications, Society of Automotive Engineers Inc., Marquette university, 1999.

[2] N.A. Fleck, R.A. Smith, Powder Metall. 3 (1981) 121-125.

[3] G. Bocchini, Int. J. Powder Metall. 22 (1986) 185-202.

[4] C.M. Sonsino, Powder Metall. 33 (1990) 235-245.

[5] M. Cristofolini, G. Pilla, A. Straffelini, A. Molinari, Design guidelines for PM parts subject to dry rolling-sliding wear, Powder Metall. 56 (2) (2013) $124-134$.

[6] A.I. Taskinen, M.H. Tikkanen, Mod. Dev. Powder Metall. 17 (1984) 545-567.

[7] H. Khorsand, S.M. Habibi, H. Yoozbashizadea, K. Janghorban, S.M.S. Reihani, H. Rahmani Seraji, M. Ashtari, Mater. Des. 23 (2002) 667-670.

[8] E.R. Leheup, D. Zhang, J.R. Moon, Wear 176 (1994) 111-119.

[9] G. Straffelini, A. Molinari, Powder Metall. 44 (4) (2001) 344-350.

[10] B. Dubrujeaud, M. Vardavoulias, M. Jeandin, Wear 174 (1995) 155-161.

[11] G. Straffelini, A. Molinari, Powder Metall. 44 (3) (2001) 248-252.

[12] N. Govindarajan, R. Gnanamoorthy, Study of damage mechanisms and failure analysis of sintered and hardened steels under rolling-sliding contact conditions, Mater. Sci. Eng.: A 445-446 (2007) 259-268.

[13] G. Straffelini, T. Marcu Puscas, A. Molinari, Identification of rolling-sliding damage mechanisms in porous alloys, Metall. Mater. Trans. A 31 (12) (2000) 3091-3099.

[14] I. Cristofolini, A. Molinari, G. Straffelini, P.V. Muterlle, A systematic approach to design against wear for Powder Metallurgy (PM) steel parts: the case of dry rolling-sliding wear, Mater. Des. 32 (4) (2011) 2191-2198.

[15] G. Hoffman, K. Lipp, K. Michaelis, C.M. Sonsino, J.A. Rice, Testing P/M materials foe high loading gear applications, Int. J. Powder Metall. 35 (6) (1999) 100.

[16] P.,Beiss Mechanische Eigenschaften von Sinterstählen. Tagungsband zum Symposium für Pulvermetallurgie: Material-Prozess-Anwendung Hagen. Vol. 27. 2003.

[17] ISO 1328-2:1997(E).

[18] Gwidon Stachowiak etc., Engineering Tribology (third ed.), 298-300.

[19] B.J. Hamrock, D. Dowson, Ball Bearing Lubrication, The Elastohydrodynamics of Elliptical Contacts, John Willey and Sons, Inc., New York, 1981.

[20] E. Bergseth, M. Torbacke, U. Olofsson, Wear in environmentally adapted lubricants with AW technology, J. Synth. Lubr. 25 (4) (2008) 137-158. 